\title{
Avaliação do impacto do treinamento sob a perspectiva da competência informacional: o caso do Portal de Periódicos da Capes
}

\author{
Fernanda Gomes Almeida \\ Mestranda; Universidade Federal de Minas Gerais (UFMG); \\ nandaalmeida@ufmg.br \\ Beatriz Valadares Cendón \\ Doutora; Universidade Federal de Minas Gerais (UFMG); \\ cendon@eci.ufmg.br
}

\begin{abstract}
Resumo: Este estudo teve por objetivo verificar o impacto dos treinamentos para o uso do Portal de Periódicos da Capes no nível da competência informacional. A metodologia foi qualitativa e a amostra da pesquisa foi formada, na primeira etapa teste pré-treinamento, por 14 alunos matriculados nos treinamentos de uso do Portal de Periódicos da Capes oferecidos à comunidade da Universidade Federal de Minas Gerais. Após o teste pré-treinamento, os estudantes passaram por uma sessão de instrução. Na segunda etapa da pesquisa - teste pós-treinamento e entrevistas, participaram sete dos 14 alunos presentes na etapa inicial. A coleta de dados foi realizada por meio de observação com gravação da tela do computador no teste prétreinamento e observação com a respectiva gravação de tela e entrevista no póstreinamento, que ocorreu duas semanas após a primeira etapa. Os dados foram coletados e analisados com base no segundo padrão da norma da ACRL Information Literacy Competency Standards for Higher Education. Conclui-se que a participação nas sessões de treinamentos influencia positivamente a obtenção e o desenvolvimento das competências informacionais.
\end{abstract}

Palavras-chave: Portal de Periódicos da Capes. Competência informacional. Avaliação. Educação superior. Treinamento de usuário.

\section{Introdução}

Este artigo relata parte de uma pesquisa de mestrado intitulada "Competência informacional no Portal de Periódicos da Capes: uma análise a partir dos treinamentos de uso", em que o objetivo foi verificar o impacto de uma sessão de treinamento de uso do Portal de Periódicos da Capes no nível da competência informacional dos discentes. Buscou-se verificar neste estudo a existência de uma 
relação positiva entre a participação do aluno em treinamento de pesquisa no Portal de Periódicos da Capes e a obtenção de competência informacional, sobretudo aquelas ligadas ao padrão 2 do documento Information Literacy Competency Standards for Higher Education” da Association of College and Research Library (ACRL) - que reza que “O estudante competente em informação é capaz de acessar a informação necessária de forma eficaz e eficiente.” (ASSOCIATION..., 2000, documento eletrônico não paginado, tradução nossa).

De acordo com Almeida (2014), a prática educativa nas bibliotecas não é nova e tem recebido diferentes denominações, tais como: orientação bibliotecária, instrução bibliotecária, instrução bibliográfica, educação de usuários, formação de usuários e outras, que muitas vezes são usadas como sinônimas. A avaliação desse tipo de instrução, segundo Lancaster (2004), é um elemento importante para os serviços oferecidos, principalmente pelas bibliotecas universitárias. Para Lancaster (2004), a avaliação da instrução bibliográfica pode ser realizada de forma objetiva ou subjetiva: a avaliação subjetiva baseia-se em opiniões, seja de participantes, instrutores ou observadores; já a avaliação objetiva tenta afastar-se dessas opiniões. Lancaster (2004) traz como exemplo de avaliação objetiva aquelas que testam os conhecimentos ou aptidões dos estudantes antes e depois da participação em programas de instrução bibliográfica, com o objetivo de identificar as mudanças verificadas após a participação em alguma atividade de instrução. Sendo assim, o autor não descarta a importância da opinião dos participantes numa avaliação, mas indica que podem ser utilizadas medidas mais objetivas para a avaliação de uma atividade.

Almeida (2014) afirma que para realizar a avaliação da competência informacional na formação dos estudantes devem-se estabelecer metas e objetivos claros, sugerindo que não sejam realizadas somente avaliações subjetivas que trabalham apenas com a opinião dos estudantes, mas sim avaliações objetivas, que permitam identificar ganhos reais em termos de aprendizagem dos estudantes. O presente trabalho avaliou o impacto das sessões de instrução sobre o Portal de Periódicos da Capes no nível da competência informacional dos estudantes de forma objetiva, utilizando roteiros de pesquisa com a respectiva gravação de tela, e de 
forma subjetiva, a partir de entrevistas, visando captar as percepções dos estudantes acerca do conteúdo proposto.

\section{O Portal de Periódicos da Capes}

O Portal de Periódicos da Capes é considerado a maior biblioteca digital de periódicos científicos do país (CENDÓN; SOUZA; RIBEIRO, 2011). Criado em 2000, o Portal Capes tem como objetivo fornecer acesso à informação científica e tecnológica de forma igualitária às instituições de ensino e pesquisa do país, reduzindo as disparidades regionais no acesso à informação (SOUZA, 2010).

Ao longo dos anos, a quantidade de conteúdo disponibilizado e a interface de pesquisa do Portal passaram por diversas mudanças. Em 2009, aconteceu uma grande mudança de interface juntamente com a aquisição e disponibilização da ferramenta de busca Metalib (máquina de busca federada) da empresa Ex Libris, que oferece um metabuscador capaz de buscar em uma mesma interface conteúdo de diversas bases de dados simultaneamente.

Em 2012, o Portal de Periódicos da Capes atualizou sua ferramenta de busca para o Metalib Plus, também da Ex Libris, que realiza uma busca centralizada no índice Primo Central Index, permitindo uma recuperação de dados com maior velocidade em todos os conteúdos pesquisáveis do Portal (COORDENAÇÃO..., 2012).

A partir de 2012, o Portal de Periódicos da Capes permitiu a realização de buscas por assunto em sua interface a partir das abordagens: busca simples - busca em uma base de metadados coletados previamente (serviço de descoberta na web) e busca avançada (busca federada), na qual se pode selecionar até 11 bases de dados para a realização das buscas. Além disso, o Portal de Periódicos da Capes ainda permite a realização de buscas por periódicos, buscas por livros e buscas por bases de dados específicas - opções "Buscar periódico”, "Buscar livro” e "Buscar base” respectivamente.

Em julho de 2014 o Portal de Periódicos da Capes sofreu uma nova alteração de interface, adequando-se ao padrão do Governo Federal em atendimento a uma 
determinação da Secretaria de Comunicação Social da Presidência da República (Secom/PR). A alteração deu-se apenas na interface, tendo sido mantidos todos os serviços e funcionalidades existentes na versão anterior, como as opções de busca disponíveis, o espaço virtual Meu Espaço e o acesso remoto via CAFe Comunidade Acadêmica Federada -, dentre outras (COORDENAÇÃO..., 2014).

\section{0 treinamento do Portal de Periódicos da Capes na Universidade Federal de Minas Gerais (UFMG)}

Desde a implantação do Portal de Periódicos, a Capes, juntamente com a UFMG, vem trabalhando para a formação de seus usuários. Entre os anos 2001 e 2004 a Capes realizou Jornadas de Treinamentos do Portal com o objetivo de capacitar bibliotecários para atuarem como multiplicadores nas instituições consorciadas. Nos anos seguintes houve uma alteração no formato dos treinamentos oferecidos pela Capes nas instituições, passando a atender não somente aos bibliotecários, mas também a todos os usuários interessados no treinamento. Ainda no ano de 2001, a Diretoria da Biblioteca Universitária/Sistema de Bibliotecas criou o Grupo de Estudos do Portal de Periódicos da Capes com o objetivo de capacitar bibliotecários do sistema de bibliotecas no uso do Portal para sua multiplicação junto à comunidade da UFMG. Esse grupo trabalhou com palestras para toda a comunidade acadêmica, programas de treinamentos específicos para cada uma das unidades acadêmicas; treinamentos na estrutura do Portal e nas bases de dados realizados em laboratórios de informática; treinamentos realizados com editores e voltados para toda a comunidade acadêmica dentre outras ações (GUIRADO; COELHO, 2008).

Ao longo do tempo, os bibliotecários perceberam que apesar de todas as ações desenvolvidas, a comunidade acadêmica ainda utilizava com pouca frequência as ferramentas disponibilizadas pelo Portal. Em 2009, a Diretoria da Biblioteca Universitária/Sistema de Bibliotecas percebeu a necessidade da criação de um setor que lidasse especificamente com as questões do Portal de Periódicos da Capes. Em janeiro de 2010 foi criado o Setor de Apoio aos Usuários do Portal. Esse setor ficou responsável pelos treinamentos nas bases de dados e na interface do Portal. Além

Avaliação do impacto do treinamento sob a perspectiva da competência informacional: o caso | 29 do Portal de Periódicos da Capes 
dos treinamentos, o setor é responsável pela intermediação entre os usuários e a Capes, visando sanar dúvidas e disseminar o conteúdo do Portal (ALMEIDA; OLIVEIRA, 2011).

Em 2010, a UFMG aderiu ao Programa de Formação de Multiplicadores do Portal de Periódicos - Pró-Multiplicar, no qual os bolsistas de mestrado e doutorado da Capes participaram de treinamentos específicos para sua área de conhecimento e após isso ficavam responsáveis por realizarem pelo menos dois treinamentos na universidade, tornando-se assim multiplicadores do conhecimento adquirido.

Atualmente a UFMG, por meio do Setor de Apoio aos Usuários do Portal Capes e demais bibliotecários alocados nas bibliotecas setoriais realizam treinamentos tanto sobre a interface do Portal Capes quanto sobre as bases de dados e ferramentas de apoio à pesquisa disponíveis. Os treinamentos, individuais ou coletivos, são realizados de forma periódica na Universidade. O Setor de Apoio ao Portal destaca-se ainda como um ponto de apoio à pesquisa científica em bases de dados dentro da Universidade.

\section{Recuperação da informação}

De acordo com Lancaster (1979), a recuperação da informação pode ser definida como o processo de buscar um conjunto de documentos a fim de identificar aqueles que tratam de um determinado assunto. Os usuários recorrem aos sistemas de informação com a intenção de satisfazer suas necessidades de informação. Para satisfazer essa necessidade, o usuário a materializa num enunciado em linguagem natural que deverá ser traduzido para uma linguagem acessível ao sistema de informação, a equação de busca. A partir daí, o sistema compara a equação de busca com a representação dos documentos, recuperando aqueles em que a representação satisfaça a equação de busca (PÉREZ GUTIÉRREZ, 2000).

De acordo com Debowski (2001), para recuperar informação, o usuário deve identificar corretamente os melhores termos para descrever o tema de pesquisa ou a necessidade de informação e, em seguida, desenvolver uma estratégia de forma eficaz para a recuperação dos itens necessários. 
A busca de informações envolve não somente o aspecto tecnológico, mas também a interação com o usuário responsável pelas especificações de busca nos sistemas de recuperação da informação em função de suas necessidades ou demandas. O usuário informa suas necessidades ao sistema por meio de estratégias ou táticas de busca, que são apresentadas na seção seguinte.

\subsection{Estratégias de busca}

A estratégia de busca, de acordo com Rowley (2002, p. 180) é “[...] o conjunto de decisões e ações tomadas durante uma busca [...]”. Hartley et al. (1990, p. 153, tradução nossa) comunga da mesma ideia e ainda acrescenta que a estratégia de busca é “[...] o conjunto total das decisões e ações tomadas durante todo o período de pesquisa, decisões que afetam os resultados em termos de itens recuperados e itens não recuperados”.

De acordo com Lancaster (1979), a preparação da estratégia de busca envolve a análise e tradução dos conceitos. Num primeiro momento, é realizada a análise do pedido para determinar o que o usuário quer e após isso é realizada a tradução da análise conceitual para o vocabulário do sistema. Quando uma busca é realizada, o sistema compara os registros para encontrar quais termos pesquisados foram encontrados. Uma das formas do sistema fazer essa comparação é com o uso dos operadores booleanos (HARTLEY et al., 1990; ROWLEY, 2002).

No modelo booleano, o documento é representado por um conjunto de termos de indexação de forma manual ou automatizada. A expressão de busca é composta pelos termos ligados pelos operadores booleanos - AND, OR e NOT - e como resposta, são apresentados os documentos que satisfazem a expressão da busca (FERNEDA, 2003). O operador AND é usado quando dois termos são combinados, retornando documentos que contenham os dois termos. Os registros que não contenham nenhum dos termos ou apenas um deles não são retornados na busca. $\mathrm{O}$ operador OR é usado para vincular semanticamente os termos relacionados, como sinônimos e as formas singular e plural dos termos. O operador NOT é usado quando se quer excluir de um conjunto de documentos aqueles que contenham um 
segundo conjunto (HARTLEY et al., 1990). Além do modelo booleano, também são utilizados modelos quantitativos para a recuperação da informação, como os modelos vetorial, probabilístico, fuzzi, booleano estendido e os modelos dinâmicos como os sistemas especialistas e outros (FERNEDA, 2003). Esses outros modelos não serão abordados neste trabalho.

\section{Competência informacional}

O conceito de "information literacy", traduzido aqui como competência informacional conforme tradução proposta por Campello (2001), foi introduzido em 1974 por Paul Zurkowski, presidente da Information Industry Association, em uma proposta submetida à National Commission on Libraries and Information Science (NCLIS).

Em 1989, a American Library Association (ALA), por meio do Presidential Committee on Information Literacy, publicou um relatório final - Presidential Committee on Information Literacy: Final Report - definindo o conceito de competência informacional e sua importância para a educação, cidadania e força de trabalho na Era da Informação (RADER, 2006). De acordo com esse relatório, todas as pessoas devem ter acesso às informações que possam melhorar suas vidas, sendo capazes de obtê-las para atender a uma ampla gama de necessidades pessoais e de negócios. Para que consigam atender às suas necessidades de informações, as pessoas devem ser alfabetizadas informacionalmente e serem capazes de “[...] reconhecer quando a informação é necessária e ter a habilidade de localizar, avaliar e usar efetivamente a informação necessária.” (AMERICAN..., 1989, documento eletrônico não paginado, tradução nossa).

Em 2000, a ACRL publica o documento Information Literacy Competency Standards for Higher Education, ganhando assim mais importância o tema da competência informacional (RADER, 2006; GASQUE, 2012).

No Brasil, de acordo com Gasque (2012, p. 28), o movimento da competência informacional "[...] surge lentamente no início do século XXI, exclusivamente no âmbito da biblioteconomia e da ciência da informação”. Apesar

Avaliação do impacto do treinamento sob a perspectiva da competência informacional: o caso | 32 do Portal de Periódicos da Capes 
do crescimento do número de publicações e pesquisadores que tratam do tema da competência informacional, Gasque (2008) admite que no Brasil as discussões sobre este assunto precisam ser intensificadas tanto na educação básica quanto no ensino superior, em que parece haver pouca preocupação em sistematizar um programa de aprendizagem para professores e alunos com conteúdos de busca e uso de informação.

No âmbito da educação superior destaca-se o documento citado anteriormente, o Information Literacy Competency Standards for Higher Education, publicado pela ACRL em 2000 (ASSOCIATION..., 2000). Esse documento define uma série de padrões e indicadores de desempenho para os estudantes de nível superior. Segundo Neely e Sullivan (2006), o documento fornece um quadro para orientar e auxiliar o desenvolvimento de indivíduos competentes em informação, possuindo cinco padrões, 22 indicadores de desempenho e 87 resultados esperados.

Quadro 1 - Padrões para competência informacional na educação superior

\begin{tabular}{|c|l|}
\hline Padrões & \multicolumn{1}{c|}{ O estudante competente em informação: } \\
\hline 1 & Determina a natureza e a extensão da informação necessária. \\
\hline 2 & Acessa a informação necessária de forma eficaz e eficiente. \\
\hline 3 & $\begin{array}{l}\text { Avalia as informações e suas fontes criticamente e incorpora as informações } \\
\text { selecionadas em sua base de conhecimento e sistema de valores. }\end{array}$ \\
\hline 4 & $\begin{array}{l}\text { Individualmente ou como um membro de um grupo, usa a informação de forma } \\
\text { eficaz para realizar um fim específico. }\end{array}$ \\
\hline 5 & $\begin{array}{l}\text { Compreende muitas das questões econômicas, legais e sociais que cercam o uso } \\
\text { de informações e acessa e utiliza informações de forma ética e legal. }\end{array}$ \\
\hline
\end{tabular}
Fonte: Elaborado pelas autoras com base em Association... (2000).

Para esta pesquisa, focaremos no padrão 2 - o estudante competente em informação é capaz de acessar a informação necessária de forma eficaz e eficiente.

De acordo com Almeida (2014), as pesquisas e estudos sobre a aplicação prática, políticas e implementação de programas de desenvolvimento de competências informacionais nos estudantes universitários brasileiros ainda são incipientes, sendo muito importante que o sistema brasileiro de educação superior invista ainda mais esforços para que a formação em competências informacionais tenha presença garantida nos currículos acadêmicos. 


\section{Metodologia}

Para atingir o objetivo de verificar o impacto dos treinamentos no uso do Portal de Periódicos da Capes no âmbito da competência informacional dos discentes, a pesquisa adotou uma abordagem qualitativa. O universo da pesquisa foi formado pelos alunos pertencentes a todos os cursos de graduação e pós-graduação da UFMG. A amostra não probabilística acidental foi definida inicialmente com oito participantes, número que foi alterado para 14 estudantes, a partir da percepção do pesquisador de que ao coletar dados de apenas oito alunos poderia se correr o risco de que esses alunos não participassem da segunda etapa da pesquisa, inviabilizando o estudo.

Todos os participantes foram recrutados via adesão voluntária aos treinamentos oferecidos pelo Setor de Apoio aos Usuários do Portal Capes e, após a inscrição para a participação nas sessões de treinamento, pela disponibilidade em colaborar com a pesquisa em dois momentos distintos.

Na primeira etapa, chamada aqui de teste pré-treinamento por ser realizada antes da participação dos estudantes na sessão de treinamento, foram utilizados como instrumentos para a coleta de dados a observação participante e a gravação de tela realizada por meio do software gratuito AutoScreenRecorder, que permite a gravação de tela diretamente do computador, capturando imagens e movimento do mouse. Na segunda etapa, o teste pós-treinamento, realizada duas semanas após o teste pré-treinamento, foi utilizada novamente a observação participante e a gravação de tela, além de uma entrevista semiestruturada com o objetivo de verificar a percepção dos estudantes acerca da sessão de treinamento, do uso do Portal de Periódicos da Capes e das habilidades de busca adquiridas após a participação na sessão de treinamento. Os testes pré e pós-treinamento foram criados com o objetivo de identificar os benefícios diretos de uma sessão de instrução, e não apenas os benefícios declarados ou percebidos pelos participantes.

De acordo com documento da ACRL Information Literacy Competency Standards for Higher Education, padrão 2 - o estudante competente em informação acessa a informação necessária de forma eficaz e eficiente. O indicador 2 deste padrão prevê que este estudante constrói e implementa estratégias de busca 
Revista da Faculdade de Biblioteconomia e Comunicação da UFRGS v. 21 , n. 1 - Jan./Abr. 2015

efetivamente projetadas. Esse indicador trabalha com cinco resultados esperados. Para esta pesquisa foram selecionados nove resultados esperados pertencentes aos cinco indicadores constantes do padrão 2 (Quadro 2) do documento da ACRL por serem considerados como aplicáveis aos objetivos do trabalho, ao objeto de pesquisa e ao tempo necessário para a avaliação. O padrão 2 é composto por cinco indicadores de desempenho e 22 resultados esperados.

Quadro 2 - Padrão 2 - indicadores de desempenho e resultados esperados selecionados para a pesquisa

Indicador 1 - Capacidade de selecionar métodos de investigação ou sistemas de recuperação de informação mais adequados para o acesso à informação necessária

\begin{tabular}{|c|c|c|}
\hline Indicador & Resultado & Descrição do resultado \\
\hline 1 & $\mathbf{D}$ & $\begin{array}{l}\text { Seleciona abordagens eficientes e eficazes para o acesso a informação } \\
\text { necessária a partir do método ou sistema de recuperação de informação de } \\
\text { investigação. }\end{array}$ \\
\hline \multicolumn{3}{|c|}{ Indicador 2 - Capacidade de construir e implementar estratégias de busca } \\
\hline Indicador & Resultado & Descrição do resultado \\
\hline 2 & B & Identifica as palavras-chave, sinônimos e termos relacionados. \\
\hline 2 & $\mathbf{D}$ & $\begin{array}{l}\text { Constrói uma estratégia de busca usando operadores booleanos, operadores } \\
\text { de truncagem e operadores de proximidade. }\end{array}$ \\
\hline 2 & $\mathbf{E}$ & $\begin{array}{l}\text { Implementa a estratégia de busca em vários sistemas de recuperação de } \\
\text { informação utilizando diferentes interfaces de usuário e motores de busca, } \\
\text { com diferentes linguagens de comando, protocolos e parâmetros de pesquisa }\end{array}$ \\
\hline
\end{tabular}

Indicador 3 - Capacidade de recuperar informações online ou de fontes pessoais usando uma variedade de métodos

Indicador Resultado Descrição do resultado

3 A Usa diversos sistemas de busca para recuperar informação de uma variedade de formatos.

Indicador 4 - Capacidade de refinar a estratégia de busca, caso necessário

Indicador Resultado Descrição do resultado

Avalia a quantidade, a qualidade e a relevância dos resultados de busca para

$4 \quad$ A $\quad$ determinar se os sistemas de recuperação de informação ou métodos alternativos de investigação devem ser utilizados.

4 B Identifica lacunas na informação recuperada e determina se a estratégia de

4 C Repete a pesquisa usando a estratégia revista, caso necessário.

Indicador 5 - Capacidade de extrair, registrar e administrar a informação ou fontes de informação Indicador Resultado Descrição do resultado

$5 \quad$ A

Seleciona entre várias tecnologias a mais adequada para a tarefa de extrair a informação necessária (copiar/colar, fotocopiar, escanear, utilizar equipamento de áudio/vídeo).

Fonte: Elaborado pelas autoras com base em Association... (2000). 
A partir da definição dos indicadores e resultados esperados selecionados para a pesquisa e das opções de busca disponibilizadas na interface do Portal de Periódicos da Capes, foram elaborados roteiros de pesquisa utilizados no teste prétreinamento e no teste pós-treinamento. Como a amostra da pesquisa poderia conter alunos de qualquer dos cursos de graduação ou pós-graduação da UFMG, optou-se por apresentar, na primeira tarefa, roteiros de temas de interesse geral e de fácil aceitação como redes sociais no teste pré-treinamento e comunicação científica no teste pós-treinamento.

A primeira tarefa consistiu em encontrar no Portal de Periódicos Capes informações a partir do tema apresentado e selecionar e salvar um artigo dentre os tipos de recursos encontrados na busca por assunto. Embora as questões utilizadas nos testes pré-treinamento e pós-treinamento não sejam as mesmas, os conceitos de competência informacional subjacentes permaneceram. A segunda tarefa consistia em buscar um periódico específico e salvar um artigo no computador. A terceira tarefa avaliava se os participantes conseguiam realizar buscas em outros sistemas, aplicando os conceitos de competência informacional em outras situações; para isto, foram identificadas e listadas por meio do Portal de Periódicos da Capes bases de dados não brasileiras, referenciais ou de texto completo, que apresentavam interfaces de pesquisa por assunto semelhantes ao Portal de Periódicos. Os participantes deveriam realizar a mesma busca proposta na primeira tarefa em pelo menos uma das bases de dados listadas na terceira tarefa.

A partir daí, foram elaborados roteiros de entrevistas sob a hipótese de que mesmo não apresentando melhoras significativas em relação à competência informacional observadas no teste pós-treinamento, os participantes poderiam relatar outros benefícios percebidos em relação: ao treinamento recebido e sua utilidade; ao uso do Portal de Periódicos; às possíveis dificuldades de uso; à forma de pesquisar antes e depois de participar de uma sessão de instrução e às habilidades de busca e sua aplicabilidade em outras situações além do Portal de Periódicos da Capes.

Participaram da pesquisa na primeira etapa da coleta de dados (teste prétreinamento) 14 alunos, sendo 13 representantes da graduação e 1 representante da pós-graduação, distribuídos em quatro sessões de treinamento realizadas durante o 
mês de junho de 2014. No teste pré-treinamento, apenas o aluno da pós-graduação já havia participado de uma sessão de treinamento anteriormente.

No momento seguinte à realização do teste pré-treinamento, os estudantes participaram de uma única sessão de treinamento com duração de 2 horas e 30 minutos abordando os seguintes tópicos: acesso ao Portal Capes (incluindo o acesso remoto); histórico e evolução da coleção; apresentação da interface; tipos de buscas disponíveis; necessidade de informação e tradução da necessidade em expressão de busca; dicas de busca (usando sinônimos e palavras relacionadas, operadores booleanos e caracteres curinga) e outras; aplicabilidade das dicas e habilidades de pesquisa em outros sistemas.

Dentre os 14 participantes da etapa inicial, participaram da segunda etapa da pesquisa sete alunos de graduação. O convite para participação na segunda etapa foi realizado por carta-convite enviada por e-mail aos 14 estudantes da etapa inicial. Dos 14 participantes da primeira etapa, oito participantes compareceram para a realização do teste pós-treinamento, destes, um participante foi descartado pelos pesquisadores devido à mudança de interface do Portal Capes, o que poderia interferir nas comparações das gravações de tela das buscas realizadas pelo participante nas duas etapas da pesquisa.

Nenhum dos participantes da segunda etapa da pesquisa havia participado de treinamento para o uso do Portal Capes além daquele ministrado durante esta pesquisa, fato importante para verificar o impacto da sessão de treinamento a que foram submetidos.

Neste trabalho serão comparados e discutidos os dados obtidos nos testes pré e pós-treinamento referentes ao segundo padrão da norma da ACRL (2000), indicador 2, resultados esperados B e D e a percepção dos entrevistados após a participação nas sessões de treinamento. O resultado esperado B (2.2.B) prevê que o estudante competente em informação identifica as palavras-chave ou frases que representam o assunto ou necessidade de informação que possui. Além disso, é capaz de identificar terminologias alternativas para a construção da estratégia de busca como sinônimos, termos relacionados, sendo estes mais amplos ou mais restritos, e termos correspondentes em outros idiomas. O resultado esperado D 
(2.2.D) aponta que o estudante competente em informação constrói uma estratégia de busca usando comandos apropriados para o sistema de busca como operadores booleanos, truncagem e operadores de proximidade. Ademais, o estudante é capaz de utilizar aspas (“”) para indicar expressões de busca ou termos compostos. Este estudante, ainda, tem o conhecimento do uso de parênteses ( ) para alterar a ordem de precedência dos termos de busca, separar conjunto de termos ou agrupar termos sinônimos.

\section{Apresentação e análise dos dados}

A análise dos dados coletados nas gravações de vídeos teve início a partir da seleção dos padrões, indicadores e resultados esperados pertencentes ao documento Information Literacy Competency Standards for Higher Education publicado pela ACRL no ano 2000. Foram selecionados apenas alguns indicadores e resultados esperados constantes do padrão 2 desse documento, conforme apresentado anteriormente no Quadro 2. As categorias para análise foram definidas a partir do padrão, indicadores e resultados esperados selecionados para a pesquisa.

A definição das categorias analíticas para os dados coletados nas entrevistas obedeceu ao critério do modelo misto proposto por Laville, Dionne e Siman (1999), no qual a construção das categorias é realizada a priori com base no referencial teórico e no roteiro de entrevista, além da inclusão e modificação de categorias a partir da leitura dos dados coletados.

Os resultados apresentados nos itens 7.1 e 7.2 foram extraídos a partir da realização da primeira tarefa proposta nos roteiros - encontrar informações por meio de um tema proposto pelo pesquisador tendo como opção mais adequada para a realização das buscas a opção Buscar assunto, ferramenta de busca disponível na interface do Portal de Periódicos da Capes - e da terceira tarefa - realizar a mesma pesquisa proposta na primeira tarefa, porém utilizando a interface de busca de uma das bases de dados listadas na primeira tarefa. 


\subsection{Identificação de palavras-chave, sinônimos e termos relacionados}

Tanto no teste pré-treinamento quanto no teste pós-treinamento, os participantes não apresentaram dificuldades quanto à identificação das palavras-chave que representavam os temas propostos nos roteiros de pesquisa. A identificação de sinônimos e termos relacionados apresentou uma ligeira melhora no teste póstreinamento, sobretudo na identificação de termos correspondentes em outros idiomas, conforme pode ser observado nos quadros abaixo (Quadro 3 e Quadro 4).

Quadro 3 - Teste pré-treinamento - resumo - Identificação de palavras-chave e palavras relacionadas

\begin{tabular}{|c|l|l|}
\hline Participante & Palavras-chave & \multicolumn{1}{|c|}{ Palavras relacionadas } \\
\hline P1 & Redes sociais & Social networks \\
\hline P2 & Redes sociais & -- \\
\hline P4 & Redes sociais & Site \\
\hline P5 & Redes sociais & Redes, sites \\
\hline P8 & Redes sociais & Social web, social media, social networks \\
\hline P12 & Redes sociais & Sociais, Facebook \\
\hline P13 & Redes sociais & -- \\
\hline
\end{tabular}

Fonte: dados da pesquisa.

No teste pré-treinamento, todos os participantes identificaram como palavrachave para a busca o termo Redes sociais. Os participantes 2 e 13 não identificaram termos relacionados para a realização dessa busca.

Os participantes 4, 5, 8 e 12 identificaram termos relacionados ao tema principal, termos não necessariamente apresentados nos roteiros de pesquisa enquanto o participante 1 apenas identificou um termo correspondente em outro idioma.

No teste pós-treinamento, os participantes foram unânimes na identificação das palavras-chave para a realização da pesquisa, Comunicação científica.

\footnotetext{
Avaliação do impacto do treinamento sob a perspectiva da competência informacional: o caso | 39 do Portal de Periódicos da Capes 
Revista da Faculdade de Biblioteconomia e Comunicação da UFRGS v. 21, n. 1 - Jan./Abr. 2015

Quadro 4 - Teste pós-treinamento - resumo - Identificação de palavras-chave e palavras relacionadas

\begin{tabular}{|c|l|l|}
\hline Participante & \multicolumn{1}{|c|}{ Palavras-chave } & \multicolumn{1}{c|}{ Palavras relacionadas } \\
\hline P1 & Comunicação científica & Divulgação científica, scientific communication \\
\hline P2 & Comunicação científica & Comunicación científica, scientific communication \\
\hline P4 & Comunicação científica & Scientific communication \\
\hline P5 & Comunicação científica & Importância da comunicação científica, comunicação \\
\hline P8 & Comunicação científica & Canais, scientific communication, scientific research \\
\hline P12 & Comunicação científica & -- \\
\hline P13 & Comunicação científica & Scientific communication \\
\hline
\end{tabular}

Fonte: dados da pesquisa.

No teste pós-treinamento, apenas o participante 12 não utilizou termos relacionados para realizar as tarefas propostas. Apesar disso, este participante conseguiu concluir a tarefa com êxito.

A partir dos resultados no teste pós-treinamento podemos considerar que os participantes 1, 2 e 13 obtiveram melhoras em relação aos resultados apresentados no teste pré-treinamento.

Enquanto no teste pré-treinamento o participante 1 identificou apenas o termo correspondente em outro idioma (social networks), no teste pós-treinamento ele foi além, identificando também termo relacionado ao tema principal da pesquisa (scientific communication e divulgação científica, respectivamente)

Já o participante 2, que não havia identificado nenhuma palavra relacionada ao tema de pesquisa durante o teste pré-treinamento, no teste pós-treinamento pode identificar termos correspondentes em outros idiomas - espanhol e inglês realizando a busca com os termos (Comunicación científica, scientific communication).

O participante 13, assim como o participante 2, não identificara termos relacionados para a realização da busca no teste pré-treinamento, porém, no teste pós-treinamento, o participante utilizou um termo correspondente ao tema principal em outro idioma, realizando a pesquisa também pelo termo (Scientific communication).

Os participantes 4, 5 e 8 mantiveram-se no mesmo patamar. O participante 4 
identificou no teste pré-treinamento o termo relacionado (site) enquanto que no teste pós-treinamento o mesmo participante identificou um termo correspondente apenas em outro idioma, o inglês - Scientific communication. O participante 5 identificou termos relacionados nos dois testes. O participante 8 identificou termos relacionados e termos correspondentes em outro idioma nas duas oportunidades: (social web, social media e social networks) no teste pré-treinamento e (canais, scientific communication e scientific research) no teste pós-treinamento.

A análise aqui apresentada não diz respeito à quantidade de termos relacionados ou de termos correspondentes em outros idiomas identificados pelos participantes, mas quanto à presença ou ausência dos termos.

\subsection{Uso de operadores booleanos, truncagem, aspas e parênteses}

Nas tarefas propostas aos participantes foram observadas apenas o uso dos operadores booleanos e truncagem com o uso do caractere curinga asterisco (*), o uso da interrogação (?), o uso de aspas e o uso de parênteses para construção da estratégia de busca tanto na interface do Portal de Periódicos da Capes quanto na interface das bases de dados. O uso de operadores de proximidade não foi considerado uma vez que a ferramenta de busca por assunto no Portal não permite o seu uso.

No teste pré-treinamento, nenhum participante utilizou operadores booleanos, truncagem, aspas ou parênteses para a construção da estratégia de busca.

No teste pós-treinamento foi percebida uma melhora em relação à compreensão e uso dos operadores booleanos para a construção da estratégia de busca, conforme apresentado no Quadro 5. 
Revista da Faculdade de Biblioteconomia e Comunicação da UFRGS v. 21, n. 1 - Jan./Abr. 2015

Quadro 5 - Resumo - Uso de operadores booleanos

\begin{tabular}{|c|c|c|}
\hline Participante & Teste pré-treinamento & Teste pós-treinamento \\
\hline P1 & -- & AND \\
\hline P2 & -- & OR \\
\hline P4 & -- & -- \\
\hline P5 & -- & -- \\
\hline P8 & -- & AND \\
\hline P12 & -- & -- \\
\hline P13 & -- & Tenta utilizar sem sucesso \\
\hline
\end{tabular}

Fonte: dados da pesquisa.

Os participantes 1, 2 e 8 utilizam de forma adequada os operadores booleanos.

P1 seleciona a opção $<<$ Buscar base $>>$ e digita $<$ Annual Reviews $>$. P1 clica no botão $<<$ Buscar $>>$. P1 clica no nome da base de dados e é redirecionado para a interface nativa da base. [...] P1 altera novamente a estratégia de busca para <scientific and communications $>$. P1 percorre e avalia a lista de resultados. P1 novamente refaz a estratégia para <scientific AND communication>. P1 percorre e avalia a lista de resultados. (Participante 1 , Teste pós-treinamento).

Nota-se que o participante 1 utiliza o operador booleano grafado com letras minúsculas (and) e com letras maiúsculas (AND), uma vez que desconhece a sintaxe utilizada pela base de dados Annual Reviews, utilizada na pesquisa.

P2 seleciona $<<$ Buscar assunto $>>$ e digita $<$ comunicação+científica $>$. P2 refaz a estratégia de busca e digita <“comunicação científica”>. P2 clica no botão $<<$ Buscar $>>$. P2 analisa os resultados. P2 refaz a estratégia de busca para <“comunicação científica” OR “comunicación científica” OR “cientific comunication”>. (Participante 2, Teste pós-treinamento).

P2 seleciona a opção $<<$ Buscar base $>>$. P2 digita o nome de outra base de dados $<$ Academic Onefile $>$ na caixa de busca $<<$ Título $>>$ da opção $<<$ Busca por título $>>$. P2 clica no botão $<<$ Buscar $>>$. [...] P2 clica no menu $<<$ Pesquisa avançada $>>$, avalia as opções e em seguida clica no menu $<<$ Busca por guia de assunto $>>$. P2 digita na caixa de busca $<$ "comunicação científica" OR "scientific comunication">. O sistema não exibe nenhum resultado. P2 clica no botão $<<$ Fechar $>>$ e desiste da busca. (Participante 2, Teste pós-treinamento).

P1 seleciona a opção $<<$ Buscar base $>>$. P2 digita o nome de outra base de dados $<$ Academic Search Premier $>$ na caixa de busca $<<$ Título $>>$ da opção $<<$ Busca por título $>>$. P2 clica no botão $<<$ Buscar $>>$. P2 clica no nome da base de dados e é redirecionado para a interface nativa da base. P2 digita na caixa de pesquisa básica <”comunicação científica” OR

Avaliação do impacto do treinamento sob a perspectiva da competência informacional: o caso 
“comunicación científica”>. (Participante 2, observações e descrição do teste pós-treinamento).

A partir da descrição dos vídeos percebe-se que o participante 2 faz uma primeira tentativa de utilização de operador booleano AND na opção Buscar assunto - <comunicação+científica>-, mas desconhece a sintaxe utilizada pelo sistema que não aceita a utilização dos sinais (-) AND (+), OR (|) e NOT (-), respectivamente. Após isso, o participante 2 refaz a estratégia de busca utilizando o operador booleano OR na interface do Portal de Periódicos da Capes (Buscar assunto) e nas buscas realizadas na interface das bases de dados Academic Onefile e Academic Search Premier. Nota-se que o uso do operador foi realizado de forma adequada, porém, algumas vezes, a busca não obteve resultados devido à grafia incorreta da palavra-chave (cientific comunication, scientific comunication).

Apesar de o operador booleano AND já ser utilizado implicitamente nas estratégias de busca, o participante 8 utiliza este operador de forma explícita na pesquisa realizada na interface do Portal Capes e na interface da base de dados escolhida para a busca, o Cambridge Journals Online. Apenas o participante 8 utiliza o recurso de truncagem para a construção estratégia de busca.

P8 seleciona novamente $<<$ Buscar assunto $>>$ e digita <"comunicação científica" $>$. P8 clica no botão $<<$ Buscar $>>$. P8 percorre e avalia a lista de resultados. P8 clica na caixa de busca e refaz a estratégia para $<$ “comunicação científica” AND cana*>. P8 clica no botão $<<$ Buscar $>>$. (Participante 8, Teste pós-treinamento).

P8 seleciona a opção $<<$ Buscar base $>>$ e digita $<<$ Cambridge Journals Online $>>$. P8 clica no botão $<<$ Buscar $>>$. P8 clica no título da base de dados e é redirecionado para a inteface nativa da base. P8 identifica e clica na caixa de busca na interface da base. P8 digita <"scientific communication” AND “scientific research”>. P8 clica no botão $<<$ Search $>>$. (Participante 8, Teste pós-treinamento).

O participante 13 faz uma tentativa de utilização dos operadores booleanos na construção da estratégia de busca, porém, por desconhecer a sintaxe utilizada pela base de dados, não obtém nenhum resultado de busca. Este participante utiliza o sinal (+) em vez de usar AND e (ou) em vez de usar o operador OR.

P13 retorna para a opção $<<$ Buscar base $>>$ e digita $<$ Annual Reviews $>$. P13 clica no botão $<<$ Buscar $>>$. P13 seleciona a base $<<$ Annual 
Reviews $>>$. O sistema redireciona para a interface nativa da base. P13 seleciona a caixa de busca por assunto e digita <"scientific communication”+“comunicação científica” $>$. P13 clica no botão $<<$ Search $>>$. O sistema não exibe nenhum resultado. P13 refaz a estratégia de busca para <"scientific communication" ou "comunicação científica” $>$. O sistema novamente não exibe nenhum resultado. (Participante 13, Teste pós-treinamento).

No pós-teste, os participantes 4, 5 e 12 não utilizaram operadores booleanos ou truncagem por meio dos caracteres curinga para a construção da estratégia de busca tanto na interface de pesquisa no Portal de Periódicos da Capes quanto na interface das bases de dados.

No teste pós-treinamento apenas os participantes 1 e 5 não utilizaram aspas para indicar expressões ou termos compostos na construção da estratégia de busca, conforme pode ser observado no Quadro 6.

\begin{tabular}{|c|c|c|}
\multicolumn{1}{|c|}{ Quadro 6 - Resumo - Uso de aspas na construção das estratégias de busca } \\
\hline Participante & Teste pré-treinamento & Teste pós-treinamento \\
\hline P1 & Não & Não \\
\hline P2 & Não & Sim \\
\hline P4 & Tenta utilizar & Tenta utilizar sem sucesso \\
\hline P5 & Não & Não \\
\hline P8 & Não & Sim \\
\hline P12 & Não & Sim \\
\hline P13 & Não & Sim \\
\hline
\end{tabular}

Fonte: dados da pesquisa.

O participante 4 faz uma tentativa de utilização das aspas - <“scientific communication comunicação científica”> - porém, não obtém resultados. O mais adequado para que se obtenha resultados em uma pesquisa seria utilizar a sintaxe <"scientific communication” OR “comunicação científica”>, ou ainda <"scientific communication" "comunicação científica”>.

Nenhum participante, nos testes pré ou pós-treinamento, utilizou parênteses na construção da estratégia de busca. 


\subsection{A opinião dos participantes}

Todos os entrevistados consideram que a participação na sessão de treinamento foi útil para eles, seja para a vida acadêmica, para o desenvolvimento das habilidades de pesquisa ou por conseguirem utilizar o Portal de Periódicos da Capes de forma mais eficiente. Além disso, todos os entrevistados afirmaram que recomendariam ou que já recomendaram o treinamento para os seus colegas. Os entrevistados consideram ainda que a participação nas sessões de treinamento proporcionou a eles condições de realizar buscas mais proveitosas.

O principal ponto positivo relatado com a participação na sessão de instrução foi a melhora na seleção da opção de busca mais adequada para cada uma das situações de pesquisa, seja para buscar assunto, periódico, livro ou base de dados. Os participantes, ainda, relataram melhoria na utilização de recursos mais específicos do Portal de Periódicos da Capes, além da busca por assunto. Além disso, os participantes entrevistados relataram ganhos relacionados ao desenvolvimento das competências informacionais voltadas para a construção da estratégia de busca com o uso de operadores booleanos, identificação de termos relacionados em outros idiomas e ao uso de aspas.

Após a participação na sessão de treinamento os entrevistados tomaram consciência de que as habilidades trabalhadas no treinamento poderiam ajudá-los em outras situações além do Portal de Periódicos da Capes, como outras ferramentas de busca. A pesquisa no buscador Google foi citada como mais beneficiada a partir do treinamento do Portal Capes, uma vez que o treinamento permitiu um aumento na percepção sobre a realização de pesquisas, uso de operadores booleanos, uso de aspas e identificação de termos relacionados.

De modo geral, as dificuldades muitas vezes persistem, mesmo após a participação na sessão de treinamento, porém de forma amenizada. No entanto, os participantes acreditam que na medida em que realizarem buscas com maior frequência e usarem mais recursos do Portal, melhores resultados serão obtidos. 


\section{Considerações finais}

A partir dos dados apresentados nas gravações de vídeo, podemos considerar que a participação nas sessões de treinamento contribuiu para o desenvolvimento das competências informacionais relacionadas aos resultados esperados 2.2.B Identificação de palavras-chave, sinônimos e termos relacionados - e 2.2.D - Uso de operadores booleanos, truncagem, aspas e parênteses. No teste pós-treinamento, apenas um participante não identificou termos relacionados ao tema de pesquisa ou termos correspondentes em outros idiomas.

No teste pós-treinamento também foi percebido um avanço em relação à compreensão e uso de operadores booleanos e de aspas para a construção da estratégia de busca. A truncagem, no entanto, foi usada por apenas um participante. Nenhum dos participantes utilizou parênteses na construção da estratégia de busca.

Os ganhos obtidos nos treinamentos muitas vezes não são tão aparentes ou perceptíveis nos participantes, se avaliados objetivamente. Por outro lado, a partir das entrevistas (avaliação subjetiva), todos os participantes relataram ganhos ou aparentaram entusiasmo com os possíveis ganhos após sua participação nas sessões de treinamento. Os participantes foram unânimes ao afirmar a importância e utilidade do treinamento. Os entrevistados destacaram como ponto positivo a seleção da opção mais adequada para a realização das pesquisas e o desenvolvimento das competências informacionais aplicadas à construção da estratégia de busca.

Como limitações do estudo apontamos a falta de um grupo de controle não participante das sessões de treinamento, o curto tempo entre a realização dos testes pré e pós-treinamento (apenas duas semanas), não sendo possível confirmar se os avanços apresentados estavam ligados à memória de curto prazo dos participantes. Devido ao curto espaço de tempo entre os testes, optou-se por utilizar roteiros de pesquisa diferentes nos dois testes com temas de pesquisa também diferentes. A aceitação ou familiaridade do participante com o tema proposto pode ter influenciado na realização das tarefas. Outra limitação seria a proposta de atividade desvinculada da real necessidade de pesquisa do estudante, fato que também pode alterar o processo de busca desenvolvido. 
Consideramos que, apesar das limitações apontadas no estudo, fica perceptível a melhora obtida pelos estudantes em relação ao desenvolvimento das competências informacionais quando comparados os resultados obtidos nos testes pré e pós-treinamento. Dessa forma, concluímos que a participação do estudante nas sessões de instrução contribui para o desenvolvimento das competências informacionais relacionadas à busca e recuperação da informação, como relatado anteriormente.

\section{Referências}

ALMEIDA, Fernanda Gomes; OLIVEIRA, Carla Cristina Vieira de. A criação de um setor de apoio aos usuários do Portal de Periódicos da Capes na UFMG. In: CONGRESSO BRASILEIRO DE BIBLIOTECONOMIA E DOCUMENTAÇÃO, 24., 2011, Maceió. Anais... Maceió: FEBAB, 2011. Disponível em:

<http://febab.org.br/congressos/index.php/cbbd/xxiv/>. Acesso em: 12 maio 2014.

\section{ALMEIDA, Maria da Graça Gomes. La integración de la alfabetización} informacional (ALFIN) en la formación del estudiante universitario: análisis de iniciativas en Brasil y España. 2014. 441f. Tese (Doctorado en Documentación: Archivos y Bibliotecas en el Entorno Digital) - Departamento de Biblioteconomía y Documentación, Universidad Carlos III de Madrid, Getafe, 2014. Disponível em: $<$ https://repositorio.ufba.br/ri/handle/ri/15488>. Acesso em: 17 jul. 2014.

\section{AMERICAN LIBRARY ASSOCIATION (ALA). Presidential Committee on} Information Literacy: final report. Chicago, 1989. Disponível em:

$<$ http://www.ala.org/acrl/publications/whitepapers/presidential>. Acesso em: 29 jul. 2013.

ASSOCIATION OF COLLEGE AND RESEARCH LIBRARIES (ACRL). Information Literacy Competency Standards for Higher Education. Chicago, 2000. Disponível em:

$<$ http://www.ala.org/acrl/standards/informationliteracycompetency>. Acesso em: 01 ago. 2014.

CAMPELLO, Bernadete dos Santos. Biblioteca escolar: temas para uma prática pedagógica. Belo Horizonte: Autêntica, 2001.

CENDÓN, Beatriz Valadares; SOUZA, Juliana Lopes de Almeida; RIBEIRO, Nádia Ameno. Satisfação dos usuários do Portal da Capes: um estudo sobre a obtenção de sucesso no uso do sistema. Perspectivas em Ciência da Informação, Belo Horizonte, v. 16, n. 2, p. 67-100, abr./jun. 2011. Disponível em: $<$ http://portaldeperiodicos.eci.ufmg.br/index.php/pci/article/view/1236> . Acesso em: 12 mar. 2012. 
COORDENAÇÃO DE APERFEIÇOAMENTO DE PESSOAL DE NÍVEL SUPERIOR (CAPES). Novo site do Portal de Periódicos da Capes. 2014. Disponível em: <http://www-periodicos-capes-govbr.ez45.periodicos.capes.gov.br/index.php?option=com_phome $>$.Acesso em: 07 jul. 2014.

COORDENAÇÃO DE APERFEIÇOAMENTO DE PESSOAL DE NÍVEL SUPERIOR (CAPES). Nova ferramenta de busca recupera dados com maior velocidade. 2012. Disponível em:

$<$ http://www.periodicos.capes.gov.br/?option=com_pnews\&component=NewsShow

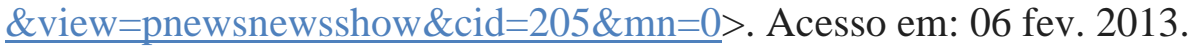

DEBOWSKI, Shelda. Wrong way: go back! An exploration of novice search behaviours while conducting an information search. The Electronic Library, Oxford, v. 19, n. 6, p. 371-382, 2001. Disponível em:

$<$ http://www.emeraldinsight.com/journals.htm?articleid=861940>. Acesso em: 03 nov. 2013.

FERNEDA, Edberto. Recuperação de Informação: análise sobre a contribuição da Ciência da Computação para a Ciência da Informação. 2003. 147 f. Tese (Doutorado) - Escola de Comunicação e Artes. Universidade de São Paulo, São Paulo, 2003. Disponível em:

<http://www.teses.usp.br/teses/disponiveis/27/27143/tde-15032004-130230/ptbr.php>. Acesso em: 03 nov. 2013.

GASQUE, Kelley Cristine Gonçalves Dias. Letramento informacional: pesquisa, reflexão e aprendizagem. Brasília: Faculdade de Ciência da Informação/Universidade de Brasília, 2012. Disponível em: $<$ http://leunb.bce.unb.br/bitstream/handle/123456789/22/Letramento_Informacional. pdf? sequence=3>. Acesso em: 17 ago. 2013.

GASQUE, Kelley Cristine Gonçalves Dias. O pensamento reflexivo na busca e no uso da informação na comunicação científica. 2008. $241 \mathrm{f}$. Tese (Doutorado) Programa de Pós-graduação em Ciência da Informação, Universidade de Brasília, 2008. Disponível em:

$<$ http://bdtd.bce.unb.br/tedesimplificado/tde busca/arquivo.php?codArquivo=3564> . Acesso em: 17 ago. 2013.

GUIRADO, Jane Rodrigues; COELHO, Maria de Fátima Pinto. O Sistema de Bibliotecas e o Portal de Periódicos da CAPES: irradiando a pesquisa na UFMG. 2008. 109 f. Trabalho de Conclusão de Curso (Especialização em Gestão Estratégica da Informação) - Universidade Federal de Minas Gerais, Belo Horizonte, 2008.

HARTLEY, R. J. et al. Online searching: principle and practice. Bowker-Saur: London, 1990. 
LANCASTER, F. Wilfrid. Information retrieval systems: characteristics, testing and evaluation. 2nd ed. New York: John Willey, 1979.

LANCASTER, F. Wilfrid. Avaliação de serviços de bibliotecas. Brasília: Briquet de Lemos, 2004.

LAVILLE, Christian; DIONNE, Jean; SIMAN, Lana Mara de Castro. A construção do saber: manual de metodologia da pesquisa em ciências humanas. Porto Alegre: Artmed, 1999.

NEELY, Teresa Y.; SULLIVAN, Katy. Integrating the ACRL stardands. In: NEELY, Teresa Y. Information literacy assessment: standards-based tools and assignment. Chicago: American Library Association, 2006. p. 6-18.

PÉREZ GUTIÉRREZ, Mario. El lenguaje de interrogación: una gramática formal para la recuperación de la información. Revista Española de Documentación Científica, Madrid, v. 23, n. 3, p. 247-266, 2000. Disponível em:

$<$ http://redc.revistas.csic.es/index.php/redc/article/viewArticle/323>. Acesso em: 03 nov. 2013.

RADER, Hannelore. Foreword. In: NEELY, Teresa Y. Information literacy assessment: standards-based tools and assignment. Chicago: American Library Association, 2006. p. v-vii.

ROWLEY, Jennifer. A biblioteca eletrônica. 2. ed. Brasília: Briquet de Lemos, 2002.

SOUZA, Katyusha Madureira Loures. Personalização de serviços de informação oferecidos na web: estudo do Portal de Periódicos da CAPES. 2010. 193 f. Dissertação (Mestrado em Ciência da Informação) - Departamento de Ciência da Informação e Documentação, Universidade de Brasília, Brasília, 2010. Disponível em:<http://repositorio.bce.unb.br/bitstream/10482/8413/1/2010_KatyushaMadureira LouresDeSouza.pdf>. Acesso em: 06 fev. 2013.

\section{Evaluating the impact of training from the perspective of information literacy: the case of Capes Portal of E-Journals}

\footnotetext{
Abstract: This study aimed at assessing the impact of training in the use of the Capes Portal of E-Journals at the information literacy level of students. The methodology was qualitative and the survey sample was formed, in the first stage pre-instruction test, by 14 students which enrolled voluntarily in a training program offered by the university library to the Federal University of Minas Gerais community. After the pre-instruction test, the students went through an instructional 
session. In the second stage of the research (post-instruction test and interviews), seven of the 14 students present at the initial stage participated. Data collection was conducted through observation and computer screen recording in the pre-instruction test and observation, computer screen recording and interviews at the postinstruction test conducted two weeks after the first stage. The data were obtained and analyzed based on the second standard of the ACRL Information Literacy Competency Standards for Higher Education. Results led to the conclusion that participation in training sessions positively influence the development and achievement of information literacy.

Keywords: Capes Portal of E-Journals. Information literacy. Assessment. Higher education. User training.

Recebido: 07/08/2014

Aceito: 09/12/2014 